\title{
Analysis and Projection of Flood Hazards over China
}

\author{
Yulian Liang ${ }^{1,3}\left(\mathbb{D}\right.$, Yongli Wang ${ }^{2, *} \mathbb{\infty}$, Yinjun Zhao ${ }^{1,3}{ }^{-}$, Yuan $\mathrm{Lu}^{3}$ and Xiaoying Liu ${ }^{3}$ \\ 1 Key Laboratory of Environment Change and Resources Use in Beibu Gulf, Ministry of Education, \\ Nanning Normal University, Nanning 530001, China; ratia_lian@163.com (Y.L.); crpp0104@163.com (Y.Z.) \\ 2 Key Lab of Regional Climate-Environment for Temperate East Asia, Institute of Atmospheric Physics, \\ Chinese Academy of Sciences, Beijing 100029, China \\ 3 School of Geography and Planning, Nanning Normal University, Nanning 530001, China; \\ luyuan@gxtc.edu.cn (Y.L.); bfc880314@163.com (X.L.) \\ * Correspondence: wangyl@tea.ac.cn; Tel.: +86-1082995141
}

Received: 30 April 2019; Accepted: 11 May 2019; Published: 16 May 2019

\begin{abstract}
Floods have been experienced with greater frequency and more severity under global climate change. To understand the flood hazard and its variation in the future, the current and future flood hazards in the 21st century in China are discussed. Floods and their trends are assessed using the accumulation precipitation during heavy rainfall process (AP_HRP), which are calculated based on historical meteorological observations and the outputs of a global climate model (GCM) under three Representative Concentration Pathway (RCP) scenarios. The flood-causing HRPs counted by the flood-causing critical precipitation (the $60 \%$ fractile of AP_HRP) capture more than $70 \%$ of historical flood events. The projection results indicate that the flood hazards could increase under RCP4.5 and RCP8.5 and increase slightly under RCP2.6 during the 21st century (2011-2099). The spatial characteristics of flood hazards and their increasing trends under the three RCPs are similar in most areas of China. More floods could occur in southern China, including Guangdong, Hainan, Guangxi and Fujian provinces, which could become more serious in southeastern China and the northern Yunnan province. Construction of water conservancy projects, reservoir dredging, improvement of drainage and irrigation equipment and enhancement of flood control and storage capacity can mitigate the impacts of floods and waterlogging on agriculture.
\end{abstract}

Keywords: heavy rainfall process; flood hazard; flood projection; RCPs

\section{Introduction}

The global mean surface has been warming since the Industrial Revolution. Global warming increases the water holding capacity of the atmosphere, and therefore hydrological cycle changes accordingly [1]. As precipitation is the primary water source for agricultural production in most parts of the world, precipitation characteristics (amount, frequency, intensity) are of great concern to agriculture [2]. Too much (floods) or too little (drought) precipitation is harmful or even devastating to crops [3]. China is the most populous country in the world and is a large agricultural country. In recent decades, droughts and floods have led to large economic and societal losses [4]. Along with climate changes, floods have been experienced globally with greater frequency and more severity [5]. With the continuous aggravation of this threat, reducing the impact and loss caused by flood disasters has become a focus issue [6]. Under the background of global warming, it is urgent to understand the increased risks associated with agricultural production to adapt to the frequency and intensity of rainstorms that occur in the rising trend [7], which is of great significance in agricultural production and economic development. In 1996 and 1998, several destructive floods occurred in the Yangtze, Yellow, Haihe and Songhua Rivers in China. For instance, extreme floods occurred in the Yangtze River during 1998, causing severe flooding that affected the lives of 8 million people [8]. An increasing trend 
of flood disasters was observed in Xinjiang since the mid-1980s [9]. Floods are also the most costly in terms of economic loss, and floods are increasing Taiwan's economic losses [10]. For developed countries, each flood can cost more than $\$ 2$ billion [11]. Scientists have been attempting to find and understand the determinants of flood disasters under the action of extreme weather. Examining the relationship between rainfall and floods is a common technique.

To measure flood, a series of indices based on precipitation have been applied [12]. Most are defined based on a single scale such as a percentile index (such as rainfall $95 \%$ value), absolute threshold (daily precipitation), duration index (rainy days), total description index [13-15] (annual precipitation), and comprehensive indices such as the SPI [16] (Standard Precipitation Index) and PSDI [17] (Parmer Drought Index). Along with global warming, considerable changes in drought and flood events have occurred in many regions of the world [18]. For each $1 \mathrm{~K}$ increase in the temperature, the atmospheric water holding capacity increases by approximately 7\% [19]. Current climate projections indicate that extreme events will become more common and severe in the future [20], so it is necessary to study the extreme precipitation in the 21st century. For future trends, changes in flood are often projected under several emission scenarios (RCP2.6 (radiative forcing reaches a maximum near the middle of the 21st century before decreasing to an eventual nominal level of $2.6 \mathrm{Wm}^{-2}$ ), RCP4.5/RCP6.0 (radiative forcing stabilizes to $4.5 / 6.0 \mathrm{Wm}^{-2}$ shortly after 2100) and RCP8.5 (radiative forcing increases throughout the 21st century before reaching a level of approximately $8.5 \mathrm{Wm}^{-2}$ at the end of the century) estimated corresponding to low emission, intermediate emission and high emission policy, respectively, according to the Representative Concentration Pathways (RCPs) scenarios in IPCC (Intergovernmental Panel on Climate Change) Ar5 [21]. Indices based on precipitation are also widely used in regional or global flood projection [22-25]. The standardized precipitation index (SPI) has been employed to monitor flood risk in Argentina, and can be applied as an effective tool for climate risk monitoring [25]. For the future extreme weather events research, the common tool is depending on CMIP5 data to analyze the intensity and frequency of the precipitation [26-31]. While, useful information is derived from the historical precipitation.

However, the above studies usually projected the denotation of flood with a single perspective of its frequency, intensity, duration or the total amount of extreme rainfall. Most are in terms of the meteorological and statistical significance and have not been associated with agricultural production and agricultural economic development. Therefore, to further investigate trends in the flood hazards in China, this paper investigates indicators that can comprehensively describe the sustainability of extreme rainfall events to fully reflect the severity and harmfulness of flood hazards on agriculture. The changes in flood hazards in the 21st century under three RCP scenarios (RCP2.6, RCP4.5 and RCP8.5) are addressed in this paper and the uncertainties of the projection are also discussed, aiming to provide a scientific basis to make rational use of agro-climatic resources and reduce the impacts of extreme climatic disasters on agriculture.

\section{Data}

\subsection{Study Area and Observation Data}

The monthly surface precipitation $0.5^{\circ} \times 0.5^{\circ}$ grid dataset (V2.0) (1981-2010) in China was used as the basic element for constructing flood indicators. The grid dataset was provided by the National Meteorological Information Center (NMIC) of the China Meteorological Administration (CMA) (http://data.cma.cn/) and was interpolated from 2472 meteorology stations of China using the Thin Plate Spline method and combined with three-dimensional geospatial information. The historical flood disaster record data for integrating with the flood indicator were obtained from the Chinese meteorological disaster almanac (2002-2011). 


\subsection{CMIP5 Projection Data}

The CMIP5 (phase 5 of the Coupled Model Inter-comparison Project) provides a rare opportunity to make use of the most advanced international coupled model system for climate change prediction and attribution analysis. The CMIP5 projection data of the daily precipitation of three RCP scenarios (RCP2.6, RCP4.5 and RCP8.5) were acquired from the outputs of seven models of CMIP5 and were obtained from the National Climate Center of China [32,33] (NCC). Table 1 lists a brief introduction to the CMIP5 models. The data were clipped to the range of $15^{\circ}-55^{\circ} \mathrm{N}$ and $70^{\circ}-140^{\circ} \mathrm{E}$ and processed uniformly to an $0.5^{\circ} \times 0.5^{\circ}$ grid degree from 2011 to 2099 to be consistent with the observation data. Historical scenario data of models from 1986 to 2005 were used to rectify the errors between the observed meteorological data and the CMIP5 data.

Table 1. Brief introduction to the CMIP5 (phase 5 of the Coupled Model Inter-comparison Project) models.

\begin{tabular}{cccc}
\hline No. & $\begin{array}{c}\text { Model Name } \\
\text { (for Sort) }\end{array}$ & Country & $\begin{array}{c}\text { Original Resolution } \\
(\text { Row } \times \text { Col) }\end{array}$ \\
\hline 1 & BCC-CSM1-1 & China & $64 \times 128$ \\
2 & CCSM4 & USA & $192 \times 288$ \\
3 & EC-EARTH & EU & $160 \times 320$ \\
4 & GFDL-ESM2G & USA & $90 \times 144$ \\
5 & IPSL-CM5A-MR & France & $143 \times 144$ \\
6 & MRI-CGCM3 & Japan & $160 \times 320$ \\
7 & NORESM1-M & Norway & $96 \times 144$ \\
\hline
\end{tabular}

\section{Methodology}

\subsection{Delimitation of Flood Hazard Indicators}

The accumulated rainfall caused by heavy rain is often difficult to drain and floods large areas of farmland, resulting in the destruction of farmland and water conservancy facilities, crop yield reduction or lack of harvest. The accumulated rainfall that can cause a flood disaster usually lasts for more than one day, and the rainfall intensity might be very strong. However, there are several criteria to define the occurrence of flood disaster caused by the heavy rain process (HRP): (1) heavy rainfall must last for a period of time; (2) rainfall reaches a certain intensity in the process; (3) accumulation precipitation reaches a certain threshold, and the threshold is not the same in different places.

In this paper, we used the HRP to express historical flood events. Definition of HRP should be meet the following criteria: (1) HRP starting with the daily precipitation $\geq 0.1 \mathrm{~mm}$ and ending with daily precipitation $<0.1 \mathrm{~mm}$ (ignoring noise caused by trace precipitation), (2) during HRP, at least one day there should be heavy rain (daily precipitation $\geq 25 \mathrm{~mm}$ [34]).

Figure 1 shows an example of defining an HRP. Figure 1A is an HRP that we are concerned about, and the accumulated precipitation of the HRP (AP_HRP) is $46.2 \mathrm{~mm}$. Figure 1B is an ignored rainfall process because its rainfall intensity does not reach the threshold. There are often interludes between rainfall processes and, because these interludes add to the drainage time, not all processes are disastrous. Figure $1 \mathrm{C}$ is the interval (drizzle or no rain), which can play a role in alleviating stagnant water and avoiding floods.

\begin{tabular}{|c|c|c|c|c|c|c|c|c|c|c|}
\hline Days & 1 & 2 & 3 & 4 & 5 & 6 & 7 & 8 & 9 & 10 \\
\hline $\begin{array}{c}24 \text { hour } \\
\text { Precipitation }(\mathrm{mm})\end{array}$ & 0.1 & 10 & 36 & 0.1 & 0.05 & 0 & 0.5 & 12 & 0.2 & 0 \\
\hline & A.He & $\operatorname{ainfa}$ & ess & & & & ffall $\mathrm{p}$ & $r_{\text {s wi }}$ & heavy & ign \\
\hline
\end{tabular}

Figure 1. Illustration of defining a heavy rain process (HRP). 
It is important to note that HRP do not always lead to flooding. The AP_HRP that can lead to flooding reaches a certain threshold that varies in different places. AP_HRP that meets the above two criteria in the historical reference period (1981-2010) is formed into a series, and the 95th percentile, 80th percentile and 60th percentile of the AP_HRP series at each grid $\left(0.5^{\circ} \times 0.5^{\circ}\right)$ were calculated The purpose was to find the maximum filtering noise and minimize missing information to determine the critical AP_HRP that can indicate the flooding in a certain area (in the grid).

Attention: For each grid calculated, the numerator of the vacancy rate is the total number of HRP without flood event records. The numerator of the missing rate is the total number in the flood event records without an HRP. The denominator is the total number of flood event records in the study validation period (2001-2010). The historical flood record data for validation were obtained from the 2002-2011 Chinese meteorological disaster almanac.

The matching rate between AP_HRP and the flood records from 2001 to 2010 is shown in Table 2. The AP_HRP can report $98 \%$ of flood events but contains too much noise (with a vacancy rate of $135 \%$, presenting more noise than information). The 60\% fractile of AP_HRP filtered some noise (reducing the vacancy rate to $18 \%$ ) and preserves most of the flood information. The 95\% fractile of AP_HRP omits a lot of information but the agreement for flood events was very high, especially for serious floods. Thus, the $60 \%$ fractile of AP_HRP (marked as AP_HRP $60 \%$ ) is the most ideal indicator of the occurrence of flood disasters for each grid, and the 95\% fractile of AP_HRP (marked as AP_HRP $95 \%$ ) can be used to represent serious floods.

Table 2. The average error magnitude of AP_HRP for reported flood events in China (2001-2010).

\begin{tabular}{cccc}
\hline Flood Days Reported by AP_HRP & Vacancy Rate (\%) & Missing Rate (\%) & Remarks \\
\hline Total AP_HRP & 135 & 2 & Indicates floods \\
over 60\% fractile of AP_HRP & 18 & 8 & \\
over 80\% fractile of AP_HRP & 10 & 34 & Indicates serious floods \\
over 95\% fractile of AP_HRP & 1 & 76 & .
\end{tabular}

Therefore, the annual accumulation precipitation over AP_HRP $60 \%$ (APyear) can be used as an indicator of the severity of flood hazards.

$$
\begin{gathered}
\text { APyear }=\frac{1}{\mathrm{~m} 1} \sum \operatorname{APyear}_{\mathrm{i}}(\mathrm{i}=1,2, \ldots, \mathrm{m} 1,) \\
\text { APyear }_{\mathrm{i}}=\sum \mathrm{AP}_{-} \mathrm{HRP}_{\mathrm{j}},\left(\mathrm{AP}_{-} \mathrm{HRP}_{1}, \mathrm{AP}_{-} \mathrm{HRP}_{2}, \mathrm{AP} \_\mathrm{HRP} \mathrm{ni}_{\mathrm{i}}>\mathrm{AP}_{-} \mathrm{HRP}_{60 \%}\right),
\end{gathered}
$$

where $\mathrm{APyear}_{\mathrm{i}}$ is the summary over $\mathrm{AP} \_\mathrm{HRP}_{60 \%}$ during each year for each grid, $\mathrm{AP} \_\mathrm{HRP} \mathrm{j}_{\mathrm{j}}$ refers to the $\mathrm{j}$-th flood-causing heavy rain event of the year and $\mathrm{m} 1$ is the number of years in the historical reference period (1981-2010 in this study).

The frequency of the annual flood hazards in a period (Fr) can be expressed as follows:

$$
\mathrm{Fr}=\frac{1}{\mathrm{~m} 1} \sum \mathrm{ni}
$$

where ni is the number of flood-causing heavy rain events which occur in the considered year, namely, the times of HRP while AP_HRP $\mathrm{j}>\mathrm{AP} \_\mathrm{HRP}_{60 \%}$.

\subsection{Changes in the Flood Hazards in 21st Century and the Uncertainty of the Projection}

Changes of the flood accumulation $(\triangle \mathrm{FA})$ in a certain year during the 21st century projected by CMIP5 models can be expressed as:

$$
\Delta \mathrm{FA}_{\mathrm{i}}=\mathrm{APyear}_{\mathrm{i}}-\mathrm{APyear}_{\mathrm{his}}(\mathrm{i}=1,2, \ldots, \mathrm{m} 2),
$$


where APyear ${ }_{\text {his }}$ is the average APyear in a historical reference period and $\mathrm{m} 2$ is the number of years in the projection (2011-2100 in this study).

For analysis of uncertainty, the coefficient of variation $\left(\mathrm{CV}_{\mathrm{FA}}\right)$ of $\triangle \mathrm{AP}$ among models is expressed as follows [35]:

$$
\mathrm{CV}_{\mathrm{FA}}=\frac{\sqrt{\left.\frac{1}{\mathrm{~N}_{\mathrm{mod}}} \sum_{\mathrm{k}=1}^{\mathrm{k}=\mathrm{N}_{\mathrm{mod}}(\Delta \mathrm{FA}}-\overline{\mathrm{\Delta FA}}\right)^{2}}}{\overline{\Delta \mathrm{FA}}} \times 100 \%,\left(k=1,2, \ldots, \mathrm{N}_{\mathrm{mod}}\right),
$$

where $\mathrm{N}_{\text {mod }}$ is the number of models and $\overline{\Delta \mathrm{FA}}=\frac{1}{\mathrm{~m} 2} \sum \Delta \mathrm{AP}_{\mathrm{i}}(\mathrm{i}=1,2, \ldots, \mathrm{m} 2)$ is the mean value of $\Delta \mathrm{FA}_{\mathrm{i}}$ of the projection period.

The projection ability of MME can vary spatially. For each grid, if $\mathrm{CV}_{\mathrm{FA}}<1$, it is considered that the credibility of the projecting result is greater than the noise, and vice versa. When $\mathrm{CV}_{\mathrm{FA}} \geq 1$, there is substantial noise in the model results that must be reduced before the results are used to describe future climate change [36,37].

\section{Results}

\subsection{Characteristics of Floods in China during the Current Period}

The AP_HRP of each grid was calculated by using the daily precipitation data from 1981 to 2010. The flood-causing critical precipitation (AP_HRP $60 \%$ ) in China mostly ranged from 50 to $100 \mathrm{~mm}$ (Figure 2a). There was a lack of data in western China (including Xinjiang, Tibet, Gansu province and some areas of Inner Mongolia, Ningxia, Shanxi, and Sichuan province), due to lack of eligible HRP or statistical significance. The $\mathrm{AP}_{-} \mathrm{HRP}_{60}$ obviously varies by latitude. In the northeast and the Yellow river basin area, $\mathrm{AP}_{-} \mathrm{HRP}_{60 \%}$ is mostly within $50 \sim 70 \mathrm{~mm}$; in the Yangtze river basin area, $\mathrm{AP}_{-} \mathrm{HRP}_{60 \%}$ ranged from 70 80 mm; $\mathrm{AP}_{-} \mathrm{HRP}_{60 \%}$ was more than $100 \mathrm{~mm}$ in the southwest Yunnan province and southern China coastal areas. However, $\mathrm{AP}_{-} \mathrm{HRP}_{95 \%}$ demonstrates geographical features (Figure $2 \mathrm{~b}$ ). AP_HRP $95 \%$ increased from north to south, with more than $150 \mathrm{~mm}$ in the northeast and north China, and reached more than $300 \mathrm{~mm}$ in southwest Yunnan and some coastal areas.

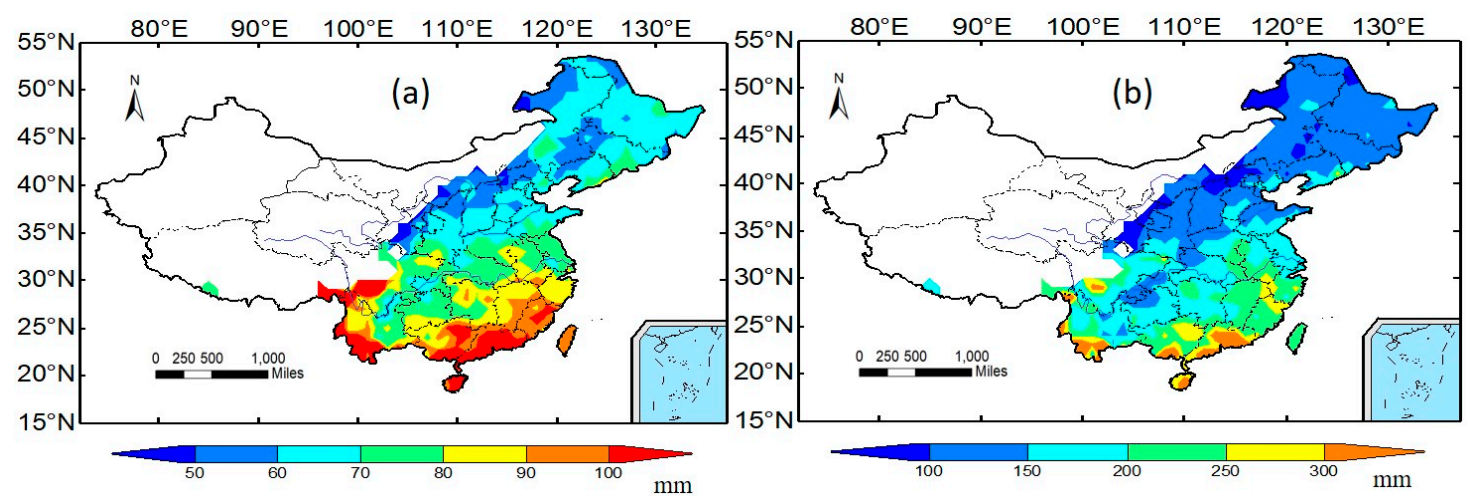

Figure 2. Flood-causing critical precipitation ((a) $\mathrm{AP}_{-} \mathrm{HRP}_{60 \%}$, unit: $\mathrm{mm}$ ) and serious flood-causing critical precipitation ((b) AP_HRP ${ }_{95 \%}$, unit: $\mathrm{mm}$ ) in China from 1981 to 2010.

Flood-causing HRPs which can be counted by flood-causing critical precipitation in each year is shown in Figure 3. Similar to the change in the AP_HRP, the frequency of flood hazards (Fr) varied from one time/year to five times/year in China, ignoring the area lacking data in northwest China (Figure 3a). The frequency in the southern area of the Yangtze River is larger than that in the area to the north ( $\mathrm{Fr} \geq 3$ ), and the four provinces of Guangdong, Guangxi, Fujian and Jiangxi have the highest frequency of flood-causing HRPs, $4-5$ per year. To consider the seasonal characteristics of flood hazard, the percentage of flood-causing HRPs in each month was counted (Figure 3b). The statistics results suggested that summer was the high-incidence season of flooding, and the flood-causing HRPs 
in JJA (June, July, August) account for over 60\% of the whole year. Flood-causing HRPs in spring (March, April, May; MAM) and autumn (September, October, November; SON) accounted for 19\% and $14 \%$, respectively.
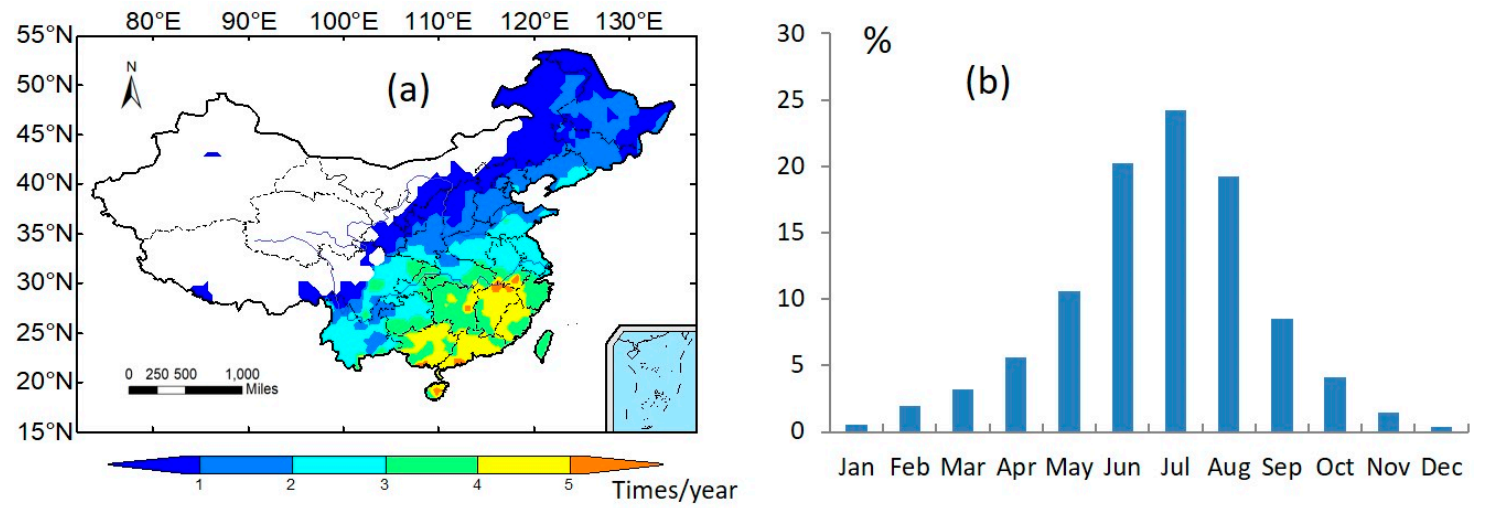

Figure 3. Frequency of flood-causing HRPs ((a), units: times/year) and their seasonal characteristics ((b), units: \%).

The spatial distribution pattern of APyear in different areas of China from 1981 to 2010 (Figure 4) was roughly consistent with the spatial distribution of flood-causing critical precipitation (Figure 2) and the frequency of flood hazards (Figure 3a). The APyear in northeast China and the Yellow River basin area was less than $200 \mathrm{~mm} /$ year. The four provinces above had the largest APyear ( $\geq 600 \mathrm{~mm} /$ year in most areas) and some areas achieved an APyear $\geq 800 \mathrm{~mm} /$ year.

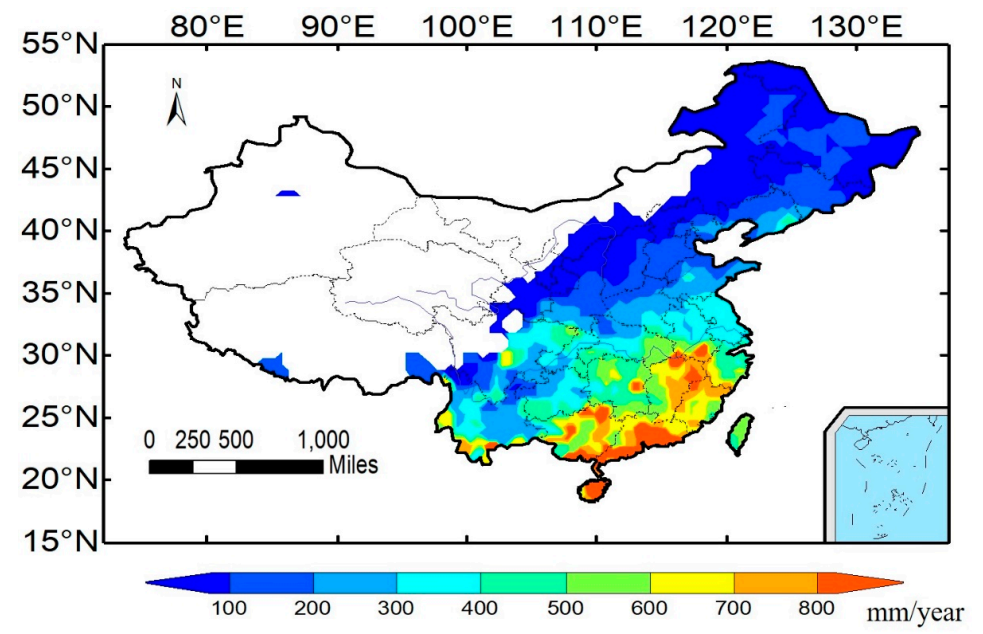

Figure 4. Distribution of APyear in China from 1981 to 2010 (units: mm/year).

\subsection{Projection of Flood Hazards in China during the 21st Century}

\subsubsection{Trends of Flood Hazards}

The projected flood accumulation changes in the 21st century under three RCP scenarios over China is shown in Figure 5. For the RCP2.6 scenario, the annual flood accumulation of multi-model ensembles (MME) would increase more than $20 \mathrm{~mm}$ in the next 90 years (Figure 5a). The growth trend of $\triangle F A$ was weak, and the correlation coefficient was low $\left(\mathrm{R}^{2}=0.183\right)$. For the RCP4.5 and RCP8.5 scenarios, the annual flood accumulation would increase significantly at a rate of $6.1 \mathrm{~mm} / \mathrm{decade}$ (Figure 5b) and $12.8 \mathrm{~mm} /$ decade (Figure 4c), respectively. Compared with the RCP2.6 scenario, $\Delta \mathrm{FA}$ presented a good correlation with time under RCP4.5 $\left(\mathrm{R}^{2}=0.701\right)$ and $\mathrm{RCP} 8.5\left(\mathrm{R}^{2}=0.930\right)$. The linear trends of the MME projection under the three scenarios all passed the significance test $(p<0.01)$. 

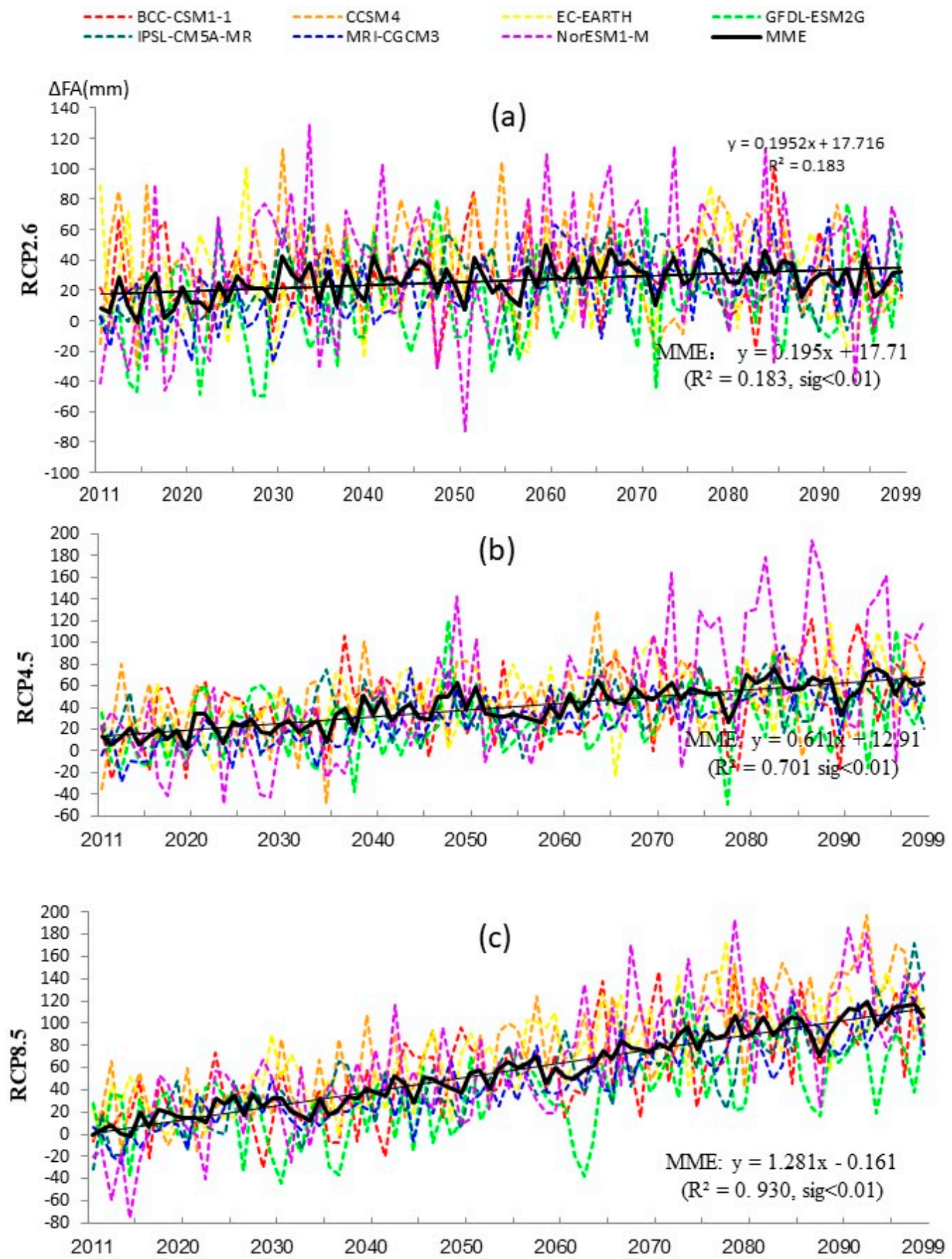

Figure 5. $\triangle \mathrm{FA}$ of China in the 21st century projected by CMIP5 models, (a): RCP2.6; (b): RCP4.5; (c): RCP8.5.

Under RCP4.5, the total increment and increase rate of annual flood accumulation are not consistent among models during the 21st century (Figure 5b). Most models believe that the annual flood accumulation in the 21st century will continue to increase. For example, the NorESM1-M model shows the most serious condition of flood hazards projection with annual flood accumulation increased $\approx 100 \mathrm{~mm}$, while the GFDL-ESM2G model shows show the minimum as $\approx 50 \mathrm{~mm}$, at the end of $21 \mathrm{st}$ century (2070-2099).

Under the RCP8.5 scenario, the difference of increment and increase rate among models are even greater than RCP2.6 and RCP4.5 (Figure 5c). The increment of annual flood accumulation among models is mostly in the range of $30 \sim 60 \mathrm{~mm}$ in the early 21st century (2020-2050), while it is in the range 
of 130 180 mm at the end of 21st century (2070-2099). The CCSM4 model shows the most serious condition of flood hazards while the GFDL-ESM2G model still shows the minimum value.

\subsubsection{Uncertainty of the Projection}

The spatial distribution of $\mathrm{CV}_{\mathrm{FA}}$ of flood accumulation among models implied that there were obvious spatial differences. For the three scenarios, the spatial patterns of the $\mathrm{CV}_{\mathrm{FA}}$ distribution were similar (Figure $6 \mathrm{a}-\mathrm{c}$ ). The regions with large $\Delta \mathrm{FA}$ variation were in northwest China (ignoring the no-data region in northwest China, as in Figure 2). Notably, the distribution of model projection uncertainties for future flooding (Figure 6) was not affected by the basic distribution patterns of flood hazards (Figures 2 and 4). The high $\mathrm{CV}_{\mathrm{FA}}$ areas did not correspond to the flood-prone area or show an obvious linear relationship. The difference in the predictions of the models in different regions was likely more related to the model performance.

Under RCP2.6 (Figure 6a), the model prediction results were relatively consistent in northeast China, the middle and lower reaches of the Yellow River, the middle and lower reaches of the Yangtze River, and southern China ( $\mathrm{CV}<0.6)$; a high coefficient corresponds with large uncertainty.

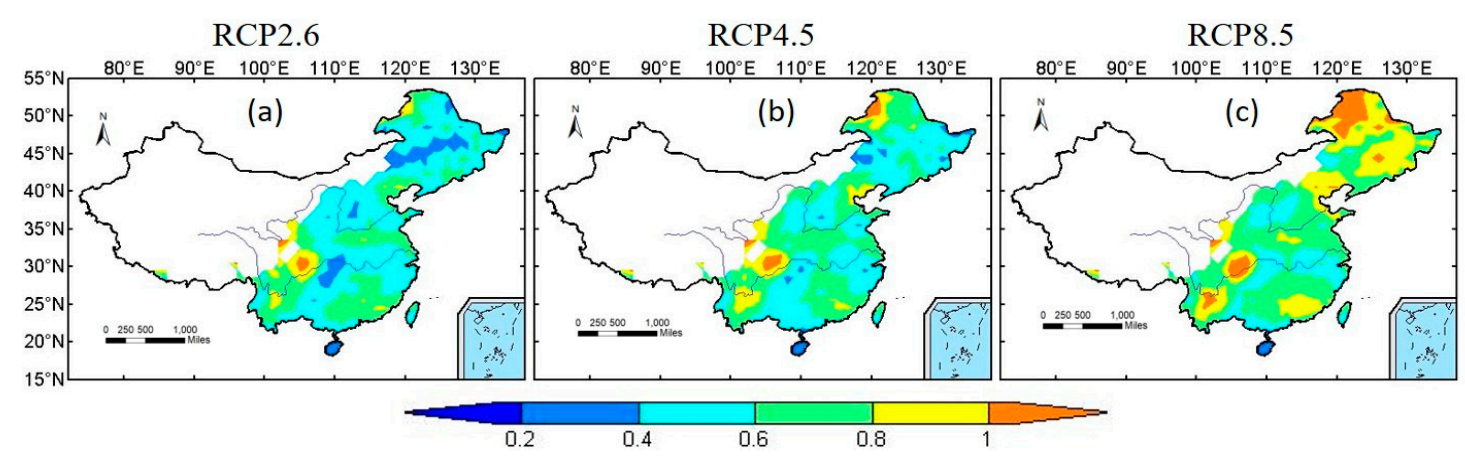

Figure 6. Coefficient of variation of flood prediction from 2011 to 2099.

Under RCP8.5 (Figure 6c), the area with $\mathrm{CV}_{\mathrm{FA}}<0.6$ appeared only in the middle reaches of the Yellow River, parts of the middle and lower reaches of the Yangtze River, and in the Hainan Province. In northeast $C$ hina, the uncertainty increases significantly. Most of this region showed a $\mathrm{CV}_{\mathrm{FA}}$ increase to $0.6 \sim 0.8$. The $\mathrm{CV}_{\mathrm{FA}}$ even exceeded 1 in the northern Heilongiiang province, and the projection results in this area were less reliable.

\subsubsection{Spatial Pattern of Flood Hazards with Confidence Regions}

The spatial distribution of $\triangle \mathrm{FA}$ under the three scenarios was also similar (Figure 7a-c). In general, the increase of $\triangle F A$ was affected by the basic distribution of APyear (Figure 4). Where the APyear was large, the corresponding increment was also large. The APyear $(\triangle \mathrm{FA})$ in southeast China (more than $600 \mathrm{~mm} /$ year in most areas) was the largest, followed by the northwest Yunnan province. However, there are some exceptions. In the Hainan province, APyear is more than $100 \mathrm{~mm} /$ year and the $\Delta \mathrm{FA}$ is less than $40 \mathrm{~mm} /$ decade. In the tropical regions, the flood hazard was serious, but the trend was not the most striking.

For the different scenarios, the more serious flood hazard would be in the highest concentration areas. For instance, the $\triangle \mathrm{FA}(20 \mathrm{~mm} /$ decade) under RCP8.5 is higher than that under RCP2.6 in most areas of China. 


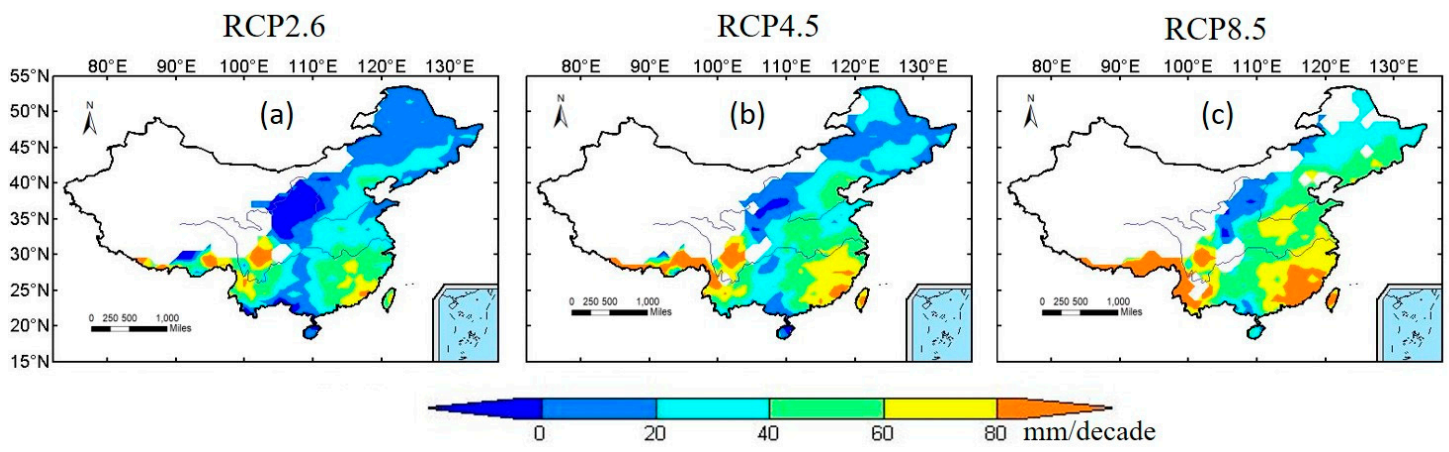

Figure 7. Spatial pattern of $\Delta F A$ from 2011 to 2099 projected by multi-model ensembles (MME) (confidence regions only, unit: $\mathrm{mm} /$ decade).

\subsection{Effects of Floods on Agriculture and Its Adaptability}

Considering seasonal change, summer was the high-incidence season for floods. Floods in the spring-summer season often increased rotten roots of wheat and rapeseed, premature aging and disease prevalence. In the midsummer period, under the effect of strong convection weather, rainstorms are usually accompanied by strong winds, which easily damage wheat and germination and cause mildew; the dry crops had rotten roots with a low seed setting rate; the rice was reduced lightly and yielded, but not harvested. Heavy rainstorms in the summer-autumn season greatly influenced the growth, development and yield of autumn crops, and even affected the harvest and sowing in autumn.

The projection results under the three RCPs showed that the flood hazards in eastern regions of China during the 21st century would present a growth situation. Although there was a growth difference among scenarios, the flood hazards always increased rather than decreased. To mitigate the impacts of flood and waterlogging on agriculture, control engineering measures should be taken, including the construction of water conservancy projects, reservoir dredging, the improvement of drainage and irrigation equipment and the enhancement of flood control and storage capacity. According to the local climate characteristics, famers should adjust the farming system to stagger the period of heavy rain and flood, to avoid disaster and ensure harvest. Agriculture administration departments should pay attention to the short- and medium-term weather forecasts, take precautions for farmland drainage and lower the water level of fish ponds. After the floods recede, it is necessary to quickly plant the crops that have been washed down by the flood, and missing seedings should be replanted in a timely manner. If the topsoil of upland crops is scoured and the root system is exposed, it must be supplemented with additional soil and intertillage topdressing fertilizer in time to improve soil conditions.

\section{Discussion}

Table 2 shows a comparison verification analysis of the flood-causing HRPs and the actual flood disaster records at a specific location. The flood-causing HRPs were basically consistent with the actual disaster records of storms and floods, and it accurately reflected the time characteristics of flood disasters in the floodplain. Individual areas and flood processes have not been accurately reflected, possibly because the occurrence of floods was also affected by factors including meteorology, especially topographical factors. For example, one region met the flood-causing conditions but the observed site may have been located at high altitude, and the drainage system was good so flood disasters did not occur easily. Though the flood-causing HRP do not inevitably lead to flooding, which could be affected by the soil moisture and human activities [12,38], the precipitation is a primary factor controlling flooding $[31,39,40]$. The accuracy prediction of the flooding process indicated that the actual occurrence rate of flooding was more than $70 \%$. It could be concluded that meteorological factors were the leading factors contributing to flooding, and the heavy rain process could more accurately describe the potential for flood disasters. Since the flood-causing HRP was based on the accumulation 
of rainfall, which was used to guide crop cropping or farming operations, it should also consider the meteorological conditions and other factors. For example, if a region had high flood-causing critical precipitation, the chance of the disaster could be reduced by improving the drainage capacity. Some hydrology literature also demonstrated that the antecedent watershed wetness was a primary factor controlling flooding in addition to precipitation [31,40].

At the end of the 21st century, the increase in precipitation in China under the three RCPs ranges from $4.04 \%$ to $12.34 \%$, with greater increases for higher-concentration pathways [37]. The rainfall period became shorter, but the intensity increased, so there may be more extreme weather in the future [20]. Figure 4 shows that the distribution of APyear and the AP_HRP were affected by the basic rainfall distribution [37]. The risk of flood hazards in humid and sub-humid areas was the largest. Flood hazards present different degrees of aggravation in different scenarios in the future, and the increasing tendency under the high concentration was the highest [27,41]. Thus, AP_HRP and $\triangle \mathrm{FA}$ used in this study did not have the same values for different regions. In different areas, the threshold value of flood-causing critical precipitation varied [28].

In addition to understanding the characteristics of the flood hazard, it was necessary to understand the related occurrence of drought in a region. The monthly proportion of historical drought events from 2001 to 2010 was calculated (Figure 8). The summer-autumn season (from June to October, accounting for more than $50 \%$ of the year) had a high incidence of drought and flood disasters (Figure $3 \mathrm{~b}$ ). Comparing the spatial differentiation of drought [35] and flooding (Figures 3a and 4), severe droughts and floods were likely to occur in the same area, and the contribution of the intensity and frequency vary [42]. Southeast China could be the region most severely affected by floods and droughts. It was prone to rapid alternation from flood to drought in the same year or showed alternating phenomena of interannual droughts and floods. Therefore, droughts and floods were not mutually exclusive in the same area, and flood-discharge and drought-resistant measures should be taken in parallel [39].

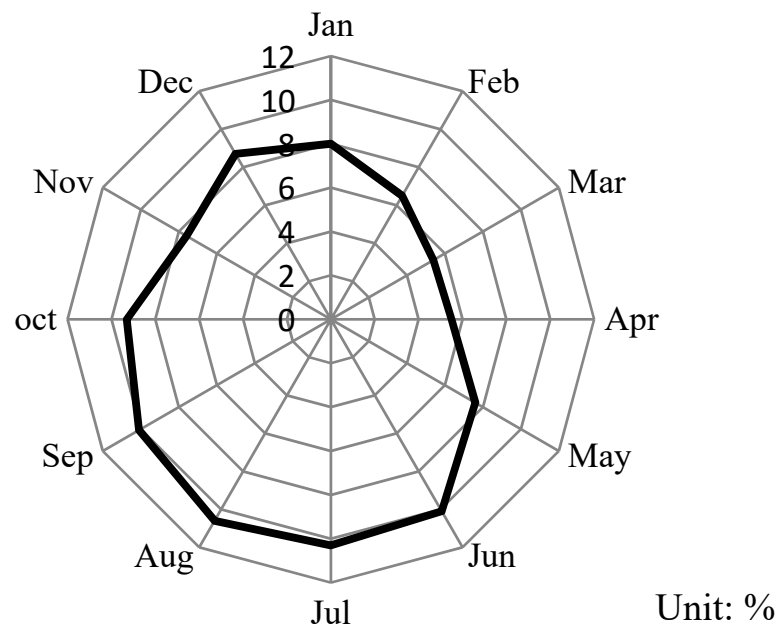

Figure 8. Drought in each month accounting for the percentage throughout the year. (The historical drought record data for validation were obtained from the 2002-2011 Chinese meteorological disaster almanac.

\section{Conclusions}

In this study, we analyzed the changes in the intensity and frequency of floods in China in the 21st century under three RCPs. Three main conclusions are summarized as follows:

1. $\quad$ AP_HRP 60 can capture most of the flood events in China.

2. The flood hazards could increase under RCP4.5 and RCP8.5 and increase slightly under RCP2.6 during the 21st century (2011-2099). The spatial characteristics of APyear and $\triangle F A$ of the three RCPs are similar in most areas of China. More flooding could occur in southern China 
(Guangdong, Hainan, Guangxi and Fujian), which could become more serious in southeastern China and the northern Yunnan province in the southwest. A higher concentration of signal corresponds to more severe flood hazard trends.

3. The MME demonstrated that the signal in the flood projection result is larger than the noise in eastern China; the noise is larger than the signal in the west, and the higher concentration of signal had greater uncertainty than the lower concentration.

Author Contributions: Y.L. (Yulian Liang) and Y.W. designed the framework. Y.L. (Yulian Liang) wrote the paper and Y.W. revised it. Y.Z., Y.L. (Yuan Lu) and X.L. conceived the study and provided comments. All authors have read and approved the final manuscript.

Funding: This study was financially supported by the National Natural Science Foundation of Guangxi, China (NO.2018GXNSFBA294019), "The Opening Foundation of Key Laboratory of Environment Change and Resources Use in Beibu Gulf Ministry of Education" (Guangxi Teachers Education University), the Guangxi Key Laboratory of Earth Surface Processes and Intelligent Simulation (Guangxi Teachers Education University) (NO.GTEU-KLOP-K1808), and the "Specially employed Expert" project of the Guangxi Zhuang Autonomous Region.

Acknowledgments: Thanks to the NNC for providing the processed CMIP5data.

Conflicts of Interest: The authors declare no conflict of interest.

\section{References}

1. Trenberth, K.E.; Dai, A.; Rasmussen, R.M.; Parsons, D.B. The changing character of precipitation. Bull. Am. Meteorol. Soc. 2003, 84, 1205-1217. [CrossRef]

2. Ma, S.; Zhou, T.; Dai, A.; Han, Z. Observed Changes in the Distributions of Daily Precipitation Frequency and Amount over China from 1960 to 2013. J. Clim. 2015, 28, 6960-6978. [CrossRef]

3. Ma, S.; Zhou, T. Observed trends in the timing of wet and dry season in China and the associated changes in frequency and duration of daily precipitation. Int. J. Climatol. 2015, 35, 4631-4641. [CrossRef]

4. Zhou, T.; Song, F.; Lin, R.; Chen, X.; Chen, X. The 2012 North China floods: Explaining an extreme rainfall event in the context of a long-term drying tendency (in “Explaining Extreme Events of 2012 from a Climate Perspective"). Bull. Am. Meteorol. Soc. 2013, 94, S49-S51.

5. Murray, V.; Mcbean, G.M.; Bhatt, M.; Borsch, S.; Cheong, S.; Erian, L.S.; Nadim, F.; Núñez, M.; Oyun, R.; Suarez, A. Managing the risks of extreme events and disasters to advance climate change adaptation. J. Clin. Endocrinol. Metab. 2012, 18, 586-599.

6. Peterson, T.C.; Alexander, L.V.; Allen, M.R.; Anel, J.A.; Barriopedro, D.; Black, M.T.; Carey-Smith, T.; Castillo, R.; Cattiaux, J.; et al. Explaining Extreme Events of 2012 from a Climate Perspective. Bull. Am. Meteorol. Soc. 2013, 94, S1-S74. [CrossRef]

7. Ma, S.; Zhou, T.; Stone, D.A.; Polson, D.; Dai, A.; Stott, P.A.; von Storch, H.; Qian, Y.; Burke, C.; Wu, P.; et al. Detectable Anthropogenic Shift toward Heavy Precipitation over Eastern China. J. Clim. 2017, 30, 1381-1396. [CrossRef]

8. Wang, Z.Y.; Plate, E.J. Recent flood disasters in China. Proce. Inst. Civ. Eng. Water Marit. Eng. 2012, 154, $177-188$. [CrossRef]

9. Jiang, F.; Zhu, C.; Mu, G.; Hu, R.; Meng, Q. Magnification of Flood Disasters and its Relation to Regional Precipitation and Local Human Activities since the 1980s in Xinjiang, Northwestern China. Nat. Hazards 2005, 36, 307-330.

10. Teng, W.-H.; Hsu, M.-H.; Wu, C.-H.; Chen, A.S. Impact of Flood Disasters on Taiwan in the Last Quarter Century. Nat. Hazards 2006, 37, 191-207. [CrossRef]

11. Karl, T.R.; Knight, R.W. Secular trends of precipitation amount, frequency, and intensity in the United States. Bull. Am. Meteorol. Soc. 1998, 79, 231-241. [CrossRef]

12. Bocchiola, D.; De Michele, C.; Rosso, R. Review of recent advances in index flood estimation. Hydrol. Earth Syst. Sci. 2003, 7, 283-296. [CrossRef]

13. Zhai, P.M.; Zhang, X.B.; Wan, H.; Pan, X.H. Trends in total precipitation and frequency of daily precipitation extremes over China. J. Clim. 2005, 18, 1096-1108. [CrossRef]

14. Harding, K.J.; Snyder, P.K. Examining future changes in the character of Central, U.S. warm-season precipitation using dynamical downscaling. J. Geophys. Res. Atmos. 2014, 119, 13116-13136. [CrossRef] 
15. Huang, X.Y.; Ullrich, P.A. The changing character of twenty-first-century precipitation over the western United States in the variable-resolution CESM. J. Clim. 2017, 30, 7555-7575. [CrossRef]

16. McKee, T.B.; Doesken, N.J.; Kleist, J. The Relationship of Drought Frequency and Duration to Time Scales. In Proceedings of the 8th Conference on Applied Climatology, American Meteorological Society, Boston, MA, USA, 17-22 January 1993; Volume 17, pp. 179-183.

17. Palmer, W.C. Meteorological drought US. Weather Bur. Res. Pap. 1965, 45, 58.

18. Lesk, C.; Rowhani, P.; Ramankutty, N. Influence of extreme weather disasters on global crop production. Nature 2016, 529, 84-87. [CrossRef] [PubMed]

19. Leung, L.R.; Qian, Y. Atmospheric rivers induced heavy precipitation and flooding in the western U.S. simulated by the WRF regional climate model. Geophys. Res. Lett. 2009, 36, 1-6. [CrossRef]

20. Battisti, D.S.; Naylor, R.L. Historical Warnings of Future Food Insecurity with Unprecedented Seasonal Heat. Science 2009, 323, 240-244. [CrossRef]

21. Taylor, K.E.; Stouffer, R.J.; Meehl, G.A. An overview of CMIP5 and the experiment design. Am. Meteorol. Soc. 2012, 93, 485-498. [CrossRef]

22. Guan, Y.; Zheng, F.; Zhang, X.; Wang, B. Trends and variability of daily precipitation and extremes during 1960-2012 in the Yangtze River Basin, China. Int. J. Climatol. 2017, 37, 1282-1298. [CrossRef]

23. William, K.M.; Lau, H.T.; Kim, K.M. A canonical response of precipitation characteristics to global warming from CMIP5 models. Geophys. Res. Lett. 2013, 40, 3163-3169.

24. Shi, Y.; Shen, Y.; Kang, E.; Li, D.; Ding, Y.; Zhang, G.; Hu, R. Recent and Future Climate Change in Northwest China. Clim. Chang. 2006, 80, 379-393. [CrossRef]

25. Seiler, R.A.; Hayes, M.; Bressan, L. Using the standardized precipitation index for flood risk monitoring. Int. J. Climatol. 2002, 22, 1365-1376. [CrossRef]

26. Gao, X.; Schlosser, C.A.; O'Gorman, P.A.; Monier, E.; Entekhabi, D. Twenty-First-Century Changes in U.S. Regional Heavy Precipitation Frequency Based on Resolved Atmospheric Patterns. J. Clim. 2017, 30, 2501-2521. [CrossRef]

27. Kundu, A.; Dwivedi, S.; Chandra, V. Precipitation Trend Analysis over Eastern Region of India Using Cmip5 Based Climatic Models. ISPRS Int. Arch. Photogramm. Remote Sens. Spat. Inf. Sci. 2014, XL-8, 1437-1442. [CrossRef]

28. Lee, J.W.; Hong, S.Y.; Chang, E.C.; Suh, M.S.; Kang, H.S. Assessment of future climate change over East Asia due to the RCP scenarios downscaled by GRIMs-RMP. Clim. Dyn. 2013, 42, 733-747. [CrossRef]

29. Lee, O.; Park, M.; Lee, J.; Kim, S. Future PMPs projection according to precipitation variation under RCP 8.5 climate change scenario. J. Korea Water Resour. Assoc. 2016, 49, 107-119. [CrossRef]

30. Scoccimarro, E.; Gualdi, S.; Bellucci, A.; Zampieri, M.; Navarra, A. Heavy Precipitation Events in a Warmer Climate: Results from CMIP5 Models. J. Clim. 2013, 26, 7902-7911. [CrossRef]

31. Shaw, S.B.; Riha, S.J. Assessing possible changes in flood frequency due to climate change in mid-sized watersheds in New York State, USA. Hydrol. Process. 2011, 25, 2542-2550. [CrossRef]

32. Dong, S.; Xu, Y.; Zhou, B.; Shi, Y. Assessment of Indices of Temperature Extremes Simulated byMultiple CMIP5 Models over China. Adv. Atoms. Sci. 2015, 32, 1077-1091. [CrossRef]

33. Zhou, B.; Wen, Q.H.; Xu, Y.; Song, L.; Zhang, X. Projected changes in temperature and precipitation extremes in china by the cmip5 multimodel ensembles. J. Clim. 2014, 27, 6591-6611. [CrossRef]

34. Grade of Precipitation, PRC National Standard; GB/T GB T 28592-2012; Science China Press: Beijing, China, 2012.

35. Liang, Y.; Wang, Y.; Yan, X.; Liu, W.; Jin, S.; Han, M. Projection of drought hazards in China during twenty-first century. Theor. Appl. Climatol. 2018, 133, 331-341. [CrossRef]

36. Li, B.; Zhou, T. Projected Climate Change over China Under SRES A1B Scenario: Multi-model Ensemble and Uncertainties. Adv. Clim. Chang. Res. 2010, 6, 270-276.

37. Liang, Y.; Yan, X.; Huang, L.; Lu, H.; Jin, S. Projection and uncertainty of climate change in China during 21st century under RCPs. J. Trop. Meteorol. 2018, 24, 102-110.

38. Sikka, A.K.; Rao, B.B.; Rao, V.U.M. Agricultural disaster management and contingency planning to meet the challenges of extreme weather events. Mausam 2016, 67, 155-168.

39. Ivancic, T.J.; Shaw, S.B. Examining why trends in very heavy precipitation should not be mistaken for trends in very high river discharge. Clim. Chang. 2015, 133, 681-693. [CrossRef]

40. Radatz, T.F.; Thompson, A.M.; Madison, F.W. Soil moisture and rainfall intensity thresholds for runoff generation in southwestern Wisconsin agricultural watersheds. Hydrol. Process. 2013, 27, 3521-3534. [CrossRef] 
41. -Oh, S.G.; Park, J.H.; Lee, S.H.; Suh, M.S. Assessment of the RegCM4 over East Asia and future precipitation change adapted to the RCP scenarios. J. Geophys. Res. Atmos. 2014, 119, 2913-2927. [CrossRef]

42. Chen, H.; Sun, J. Projected change in East Asian summer monsoon precipitation under RCP scenario. Meteorol. Atmos. Phys. 2013, 121, 55-77. [CrossRef]

(C) 2019 by the authors. Licensee MDPI, Basel, Switzerland. This article is an open access article distributed under the terms and conditions of the Creative Commons Attribution (CC BY) license (http://creativecommons.org/licenses/by/4.0/). 